\title{
EDITORIAL
}

\section{SOBRE A LIBERDADE INDIVIDUAL NA EXPERIÊNCIA CONSTITUCIONAL ITALIANA ${ }^{1}$}

\section{ON INDIVIDUAL FREEDOM IN ITALIAN CONSTITUTIONAL EXPERIENCE}

Não é tarefa desta breve nota refazer o itinerário por meio do qual, a partir das mais antigas declarações de direitos, estabeleceu-se o relacionamento entre o constitucionalismo e os valores de liberdade que qualificam a experiência constitucional europeia e que integram o seu patrimônio comum. ${ }^{2}$ Também não é o caso de atender às diferentes facetas que essa ligação conheceu sob o aspecto conceitual: em particular, à descrição jusnaturalista sobre a função essencialmente cognitiva das declarações constitucionais a respeito do "natural" estado de liberdade do homem, ou à variante simplificada, no exterior, da colocação da liberdade na categoria do "óbvio", ou do que é reconhecível na sua imediata e racional evidência.

Cabe recordar, no entanto, que a partir do reconhecimento da díade liberdade-propriedade - estabelecida nas Cartas setecentistas com o atributo da sacralidade - o constitucionalismo assumiu a tarefa de assegurar a existência de uma esfera da vida material individual e coletiva destacada das razões de Estado, de tal modo que a capacidade e os projetos dos indivíduos pudessem ser livremente desenvolvidos.

Tratava-se de um paradigma que emergiu no quadro do liberalismo jurídico - o de um modo de pensar as tarefas do Estado selecionadas de forma a manter sua compatibilidade ou, ao menos, manter um espaço adequado ao fecundo desenvolvimento das autonomias privadas. A exigência da "segurança", também invocada nas primeiras Cartas, não nega esses postulados, resolvendo-se na reivindicação de limitação e de previsibilidade da ação pública que acompanhou os principais institutos

\footnotetext{
" Professor Ordinário de Instituições de Direito Público, Departamento Ciência Política Sapienza, Università di Roma, Italia; Conselheiro editorial da Espaço Jurídico Journal of Law; robertonania@hotmail.com

1 A primeira versão deste texto foi publicada, em italiano, na Revista Percorsi Costituzionali, n. 1/2010. Esta tradução para a Língua Portuguesa se baseou na versão publicada em: NANIA, Roberto (a cura di). L'evoluzione costituzionale delle libertà e dei diritti fondamentali: saggi e casi di studio. Torino: G. Giappichelli Editore, 2012. A tradução, bem como os acréscimos de artigos do Texto Constitucional italiano e referências à jurisprudência constitucional é responsabilidade de Carlos Luiz Strapazzon, Editor-Chefe da EJJL, Professor PPGD da Universidade do Oeste de Santa Catarina de Chapecó, e Professor de Direito Constitucional da Universidade Positivo, Curitiba, PR. Esta tradução contou com a especial colaboração de Adilso Antonio Santin, mestrando do PPGD da Universidade do Oeste de Santa Catarina.

2 A respeito desse itinerário, em uma ampla perspectiva, ver HUNT, L. La forza dell'empatia, una storia dei diritti dell'uomo. Bari: Editori Laterza, 2010.
} 
que assinalaram a consolidação do Estado de direito. ${ }^{3}$ É igualmente perceptível que a plausibilidade desse desenho também se embasa na obrigação de não condicionar o exercício da própria liberdade à interferência no espaço alheio, uma obrigação tão decisiva que não se relaciona com a adesão individual espontânea, mas com as determinações legais, as quais se apresentam também como garantia e limite da liberdade individual.

Como é amplamente sabido, o quadro constitucional foi mudando profundamente no que diz respeito a esses axiomas originários. Basta pensar no ingresso, no terreno constitucional, dos direitos sociais que restam, em grande medida, descoordenados quanto às modalidades de sua realização, em respeito ao corolário da autossuficiência e independência dos poderes públicos, desde muito constitutivos das liberdades clássicas. Direitos que, de fato, encontram seu fundamento específico de valor mais na ideia de igual dignidade do que na de liberdade (senão sob a fórmula, mais sugestiva do que juridicamente fundamentada, a "liberdade do querer"), e que, por conseguinte, tocaram no senso da legitimação da presença pública e do crescimento dos poderes estatais de natureza prestacional. ${ }^{4}$ Adicione-se a isso o papel fundamental dos sistemas democrático-pluralísticos referidos nas constituições, cada vez mais assentados na ideia da participação do cidadão na dinâmica da esfera pública e que, postulando o reconhecimento de uma multiplicidade de direitos orientados para esse fim, rejeitam o conflito anterior entre a liberdade dos antigos e a liberdade dos modernos. ${ }^{5}$

Assim, o constitucionalismo assume, ao longo do tempo, uma fisionomia bem articulada na qual se instalam, sob a espécie de diversas categorias de direitos, todas as várias instâncias de proteção que amadureceram e que devem alcançar todas as necessidades do homem/cidadão.

Dito isso, é igualmente verdadeiro que as liberdades individuais transitaram incólumes por essas estreitas passagens do constitucionalismo. Na verdade (afora as liberdades econômicas contra o que, como se verá, pesaram duras críticas, sejam internas ou externas, evidenciadas pelo concreto funcionamento do mercado), a exigência de proteção do indivíduo conseguiu um grau mais elevado de garantias, a começar pela subtração das situações jurídicas reconhecidas pelas leis anteriores - e mais genericamente pela "natureza precária" abordada por Fest ${ }^{6}$ - em virtude da afirmação da rigidez constitucional.

A Constituição italiana também se moveu por essa linha de reafirmação após a experiência autoritária que interrompeu o caminho aberto pelo Statuto, com

\footnotetext{
3 Pela centralidade de tal aspecto, ver DENNINGER, E. Diritto dell'uomo e Legge fondamentale. Torino: Giappichelli,1998.

4 Sobre a manutenção, especialmente em face do complexo sistema de segurança social que somente aumentou com o passar do tempo, da necessária tensão entre a responsabilidade individual e a tutela social, ver. RITTER, G. A.

5 Ver RIDOLA, P. Libertà e diritti nello sviluppo storico del costituzionalismo, in Diritti Costituzionali, a cura di R. Nania e P. Ridola, Torino, v. 1, 74 p., 2006.

6 FEST, J. La natura precaria de la libertá. Elogio della borghesia. Milano: Harzanti Libri, 2010.
} 
a codificação dos direitos inerentes à inviolabilidade da esfera privada. Não obstante o distanciamento da imposição mais rigorosamente individualista acerca do significado da liberdade que emergiu da famosa agenda Dossetti, foi impresso o atributo de "inviolável" aos direitos aos quais é tarefa, ou âmbito de competência, do indivíduo decidir: a liberdade pessoal e de circulação, a liberdade domiciliar e de comunicação privada e o direito de defesa, com exigibilidade imediata contra qualquer eventualidade lesiva.

Uma qualificação que se pode discutir mais adiante sua exata definição jurídica, mas que ainda assim vale a pena testemunhar - em razão da sua continuidade simbólica com as antigas declarações de direitos - a dimensão individual constituía, e não poderia ser diferente, algo preliminar e irrenunciável para o novo Texto Constitucional dos direitos fundamentais. ${ }^{7} \mathrm{O}$ que significa que, em relação a tais liberdades - conclusão que também se aplica a outros direitos constitucionalmente tutelados - mesmo que alcançáveis apenas pela via reconstrutiva (e em primeiro lugar, a liberdade de manifestação de pensamento), vem implícita a carga qualitativa especial em relação à identidade constitucional e a seu sistema de valores. Por consequência, exclui-se ao menos o seu núcleo essencial do poder de revisão constitucional; em todo caso, é ônus de tal poder justificar também a finalidade de eventuais acréscimos, mas nunca de redução, do nível de tutela e de proteção que devem ser garantidos.

Excessiva, portanto, parece ser a preocupação evocada à época da Constituinte, de que a representação constituinte apresentasse uma contradição interna tanto irresolúvel quanto potencialmente perigosa para a liberdade dos indivíduos. Alude-se à hipótese de que o enunciado que prescreve o dever inderrogável de solidariedade, no Art. $2^{\circ}$ da Constituição, acabaria por perfilar uma cláusula geral e difusa de sociabilidade suscetível de restringir a liberdade do indivíduo, direcionando-a a outros objetivos e desconhecendo, assim, a mais íntima essência da dimensão privada da vida. Tratava-se de uma absolutização do modelo setecentista de Constituição como ato preordenado no caminho exclusivo de uma declaração das liberdades individuais, que não deveria ser contaminado por qualquer outro componente que pudesse ofuscar a evidência e a univocidade de seu papel. Uma crítica na realidade bem compreensível, mas que apontava com injustificada apreensão para o excesso da evocação em sede constitucional daquela atitude social da pessoa, ainda que esse dever não se colocasse de imediato como uma negação da personalidade individual, mas como uma representação mais acabada da rede de relações que acompanha o exercício da liberdade e o desenvolvimento da personalidade, graças ao que, ambos têm a oportunidade de se realizar.

Por outro lado, tais preocupações poderiam ser explicadas também pelos tipos de cautelas garantistas específicas para as disposições constitucionais de liberdade, pois encontramos um conjunto concentrado de técnicas de tutela que, de certo

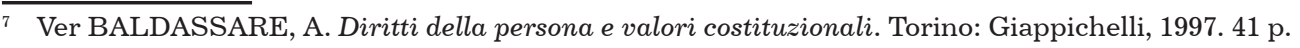


modo, habilitam todos os sujeitos públicos potencialmente autorizados a interferir na dimensão privada: pensemos nas predeterminações constitucionais dos poderes de polícia, na reserva legal acompanhada do cânone da taxatividade das tipificações penais, na reserva de provimento jurisdicional com a contemporânea codificação da regra de imediata recorribilidade na cassação dos provimentos privativos de liberdade pessoal, e por aí afora.

Pode-se lamentar certa insuficiência na formulação de tais garantias, por exemplo, no que diz respeito às modalidades oficiosas de habeas corpus, ou seja, a falta de uma garantia explícita de liberdade física, bem como de liberdade moral, ou mesmo a falta de previsão de recurso diretamente destinado à Corte Constitucional em caso de violação a direitos fundamentais. No entanto, parece excessivo dizer, muito embora os temas enumerados sejam abertos e mereçam sempre renovada atenção, que tenha sido comprometida a rigidez constitucional do sistema de garantias individuais. Nem é preciso dizer que, mediante técnicas apropriadas de interpretação, tem sido possível conduzir às devidas consequências o escopo das disposições constitucionais de maneira a atualizar sua configuração protetiva. É o caso, entre muitos exemplos similares, na atração do Art. 13 da Constituição ${ }^{8}$ para replicar a mesma liberdade moral a modalidades de interferência no âmbito privado que prescindem do condicionamento físico do indivíduo, mas não inibem menos a faculdade de autodeterminação. ${ }^{9}$

Claro, não se poderia afirmar, posto que nessa sede a abordagem retrospectiva é sempre aproximativa, que tenham sido adequadamente desenvolvidas em todas as suas implicações as potencialidades inerentes dessas preposições constitucionais estabelecidas para proteger as liberdades individuais. É notável como a temática da liberdade pessoal ocupou, por longo tempo, uma posição marginal, quase ofuscada pela preponderância assumida pelos direitos de natureza coletiva - de reunião, de associação, de greve - atrás dos quais se agitavam as dolorosas dinâmicas políticas que marcaram a história italiana e as compactas estruturações sociais e ideológicas que as protagonizavam; não por acaso, quando isso acontecia, podia-se claramente entender a funcionalidade da polêmica em torno da ampliação de oportunidades de ação política mais que a realização das, em si mesmas neutras, instâncias gerais de garantia em favor do indivíduo. Em suma, a mesma discussão sobre a natureza das disposições constitucionais, voltada à contestação de seu caráter pretensamen-

\footnotetext{
8 Art. 13 da Constituição Italiana, de 1947: A liberdade pessoal é inviolável. Não se admite qualquer forma de detenção, de inspeção ou busca pessoal, nem qualquer outra restrição de liberdade pessoal se não por um ato motivado de uma autoridade judiciária e apenas em casos e na forma prevista em lei. Em casos excepcionais de necessidade e urgência, estritamente definidos por lei, as autoridades de segurança pública podem adotar providências provisórias que, no entanto, devem ser comunicadas no prazo de quarenta e oito horas às autoridades judiciárias; se tais medidas não forem ratificadas nas próximas 48 horas, presumem-se revogadas e tornam-se nulas e sem efeito. Será punida qualquer violência física ou moral contra pessoas, ainda que sujeitas a restrições de liberdade. A lei estabelecerá o período máximo de detenção preventiva. (N.T. Versão da última atualização de abril de 2012, disponível no site da legislação vigente, em: www.normattiva.it)

9 Ver NANIA, R. La libertá individuale nella esperienza costituzionale italiana. Torino: Giappichelli, 1989 , p. 33 e ss.
} 
te programático, privilegiava os princípios constitucionais considerados essenciais para os projetos de transformações (a iniciar pela igualdade substancial considerada no segundo parágrafo do Art. $3^{\circ}$ da Constituição ${ }^{10}$ ), bem mais do que aqueles dispositivos que previam um conteúdo puramente liberal e, por isso mesmo, inadequados até para os fins de cristalização do status quo.

Além disso, não se pode esquecer que os preceitos constitucionais foram longamente confrontados com a legislação recepcionada, marcada por seus valores não liberais, como evidencia a questão das medidas de prevenção, que tanto exigiram da jurisprudência constitucional em relação a seu compromisso com a "civilização"11. Também não se deve omitir que nem bem havia transcorrido o tempo da seleção das matérias normativas anteriores logo surgiu, após o violento dissenso político, uma fundada demanda por segurança e por medidas adequadas aos fins constitucionais (pensemos no tema da duração da prisão cautelar) que, não obstante as tentativas de conter o impacto do novo Texto Constitucional pelo argumento da transitoriedade, bem como o da delimitação dos crimes pertinentes, que determinou a oscilação do pêndulo para a sensibilidade coletiva, distanciando-o, assim, da diretriz do desenvolvimento das garantias individuais.

Em consequência, nada simples se revelou a desejada realização de um sistema processual-penal que, em consonância com os novos princípios constitucionais, fosse centrado na ratio do sistema acusatório. Tanto é assim que somente com a Legge Costituzionale n. 2, de 1999, que estabeleceu a nova redação ao Art. 111 da Constituição; ${ }^{12}$ o due process of law foi finalmente elevado a princípio constitucional, oferecendo uma detalhada enunciação das garantias processuais, com particular respeito à regra do contraditório na formação da prova. Um princípio que também

\footnotetext{
10 Art. $3^{\circ}$ da Constituição Italiana, de 1947: Compete à República remover os obstáculos de natureza econômica e social que restringem a liberdade que, limitando de fato a liberdade e a igualdade dos cidadãos, impedem o pleno desenvolvimento da pessoa humana e a participação efetiva de todos os trabalhadores no desenvolvimento político, econômico e social do país. (N.T. Versão da última atualização de abril de 2012, disponível no site da legislação vigente, em: www.normattiva.it).

11 Ver ELIA, L. Libertá personale e misure de prevenzione. Milano: Garzanti Libri, 1962.

12 Art. 111 da Constituição Italiana, de 1947: A Jurisdição será implementada por meio do devido processo regulado pela lei. Cada processo se desenvolve a partir do contraditório entre as partes, em condições de igualdade diante de um juiz, terceiro e imparcial. A lei assegura duração razoável ao processo. No processo penal, a lei assegura que a pessoa acusada de um crime seja, no mais breve tempo possível, informada confidencialmente da natureza e da causa da acusação a seu respeito; tenha o tempo e as condições necessárias para a preparação de sua defesa; tenha o direito, diante do juiz, para questionar ou fazer interrogar as pessoas que fazem declarações a seu respeito, de obter a convocação e o interrogatório de pessoas para a sua defesa nas mesmas condições dadas à acusação e à obtenção de qualquer outro meio de prova a seu favor; seja assistida por um intérprete, se não compreender ou não falar a língua usada no processo. O processo penal é regido pelo princípio do contraditório na formação de provas. A culpa do réu não pode ser provada com base em declarações de pessoas que, por livre escolha, sempre for voluntariamente evitada pelo acusado ou por seu advogado. A lei regulará os casos em que a formação da prova não seguir o contraditório com o consentimento do réu ou quando se verificar essa impossibilidade pela natureza objetiva ou pelo efeito de conduta ilícita comprovada. Todas as decisões judiciais devem ser justificadas.Contra as sentenças e contra decisões que afetam as liberdades individuais, pronunciadas por órgãos jurisdicionais ordinários ou especiais, é sempre possível recorrer de Cassação por violação da lei. Pode-se renunciar a essa regra apenas pela Sentença de tribunais militares em tempo de guerra. Contra as decisões do Conselho de Estado e do Tribunal de Contas, o recurso de Cassação será admitido apenas pelas razões inerentes à respectiva jurisdição. (N.T. Versão da última atualização de abril de 2012, disponível no site da legislação vigente, em: www.normattiva.it).
} 
se irradiou sobre o processo administrativo, em sintonia com as garantias participativas previstas em sede de atividade administrativa e originárias das regras de bom desempenho e imparcialidade da administração pública.

Chegando à privacy, entendida no seu sentido de confidencialidade da vida privada e dos dados pessoais, não pode surpreender, à luz das considerações expostas, que esta também foi subestimada. De novo por conta, como foi estigmatizado, ${ }^{13}$ do prejuízo decorrente do pretenso caráter apolítico e socialmente circunscrito, da relativa reivindicação. Embora fosse imediatamente dedutível do contexto das disposições constitucionais voltadas à proteção do indivíduo, que tinham incorporado amplamente essa exigência protetiva, especialmente por força das formulações do Art. $15^{14}$ da Constituição em matéria de comunicação privada, em que há disposição expressa sobre o "sigilo de correspondência" como bem jurídico constitucional, o que deve resultar em um impacto muito negativo na regulamentação das interceptações telefônicas. Consequências que foram cuidadosamente evidenciadas na jurisprudência constitucional a partir da Sentença n. 34, de 1973, ${ }^{15}$ em que pese esta ter desconsiderado a tese de serem absolutamente inconciliáveis o instrumento investigativo da escuta clandestina e a proteção intensa estabelecida na disposição constitucional. A tal respeito, foi necessário esperar pela institucionalização do Garante ${ }^{16}$ em 1997 e pela disciplina do uso das informações pessoais, enquanto a questão da proteção da reserva domiciliar e de comunicação ainda aguarda uma solução que se possa reputar constitucionalmente adequada.

Como já mencionado, os direitos clássicos de conteúdo econômico mantiveram reconhecido seu status de direito constitucional, ainda que agora associados a cláusulas indeterminadas de interesse social, por trás das quais transparecem diversas razões, mas, sobretudo, a dura polêmica nos confrontos da dimensão possessiva do individualismo e dos seus resultados considerados necessariamente egoístas. Quanto a esse aspecto, parecia negativa a original conexão entre a liberdade e a capacidade de iniciativa no campo econômico, como fica evidente pela exclusão da liberdade econômica do campo dos direitos invioláveis e da consequente deminutio, em termos de garantias, que a elas deveria receber: a ideia, por um lado bastante difusa, mas também encontrada em sede doutrinária, do quase ilimitado poder de conformação do Poder Público, com referência específica à propriedade privada, mas também à liberdade de empresa, são as provas mais evidentes; assim como foi a tese, mais ou menos conscientemente chancelada, da relação necessariamente

\footnotetext{
13 Ver, RODOTÀ, S. Intervista su privacy e libertà. Bari: Editori Laterza, 2005.

14 Art. 15 da Constituição Italiana, de 1947: A liberdade e o sigilo da correspondência, e de qualquer outra forma de comunicação, são invioláveis. Sua limitação pode apenas ser imposta pela autoridade judicial com as garantias estabelecidas por lei. (N.T. Versão da última atualização de abril de 2012, disponível no site da legislação vigente, em: www.normattiva.it).

15 Disponível em: <http://www.cortecostituzionale.it/stampaPronunciaServlet?anno=1973\&numero=34\&tipoView $=\mathrm{P}[\mathrm{N} \cdot \mathrm{T}]>$.

16 Ver, Legge n. 249, de 31 de julho de 1997, Istituzione dell'Autorita per le garanzie nelle comunicazioni e norme sui sistemi delle telecomunicazioni e radiotelevisivo. Disponível em: <www.camera.it/parlam/leggi/972491.htm [N.T.]>.
} 
antagônica entre a liberdade de empresa e os direitos sociais, que outra saída não encontrou senão aquela da progressiva ampliação do intervencionismo público em que cada antítese, ilusoriamente, teria de se resolver.

Bastam essas rápidas alusões para confirmar a "fraqueza", obviamente sob o perfil específico de uma avaliação constitucional, de que foram acusadas as liberdades econômicas, quase esquecendo a peremptória, e sempre sugestiva, asserção schmittiana da inafastável precedência do momento da produção em face daquele da distribuição. Uma condição de fraqueza que foi utilmente ignorada pelo processo de integração europeia e pelos princípios que guiaram seu desenvolvimento, inspirados em uma mais adequada valorização das liberdades econômicas em relação à ratio da economia de mercado. A incidência interpretativa de tais princípios, ainda que simétrica em relação ao desenvolvimento competitivo aberto pela criação do mercado único, demandou a nós, italianos, a redescoberta do conteúdo essencial e indisponível das liberdades e do valor, nelas contido, dos fatores decisivos para a preservação e para o aumento do bem-estar coletivo. Falta ainda, mas é apenas uma questão de detalhamento, criar um quadro regulador idôneo apto a preservar as características concorrenciais do mercado e também as novas necessidades de tutela dos consumidores, assim como apto a lidar com os excessos especulativos que possam surgir.

São conquistas que não podem ser revogadas pelas dúvidas decorrentes da recente crise financeira, quiçá pela maximização, em nome da recuperação de uma presumida vontade originária do constituinte, daquele componente dirigista que estava presente em nossa constituição econômica e que freou a capacidade de desenvolvimento. São retrocessos que pareceriam ainda mais irrealistas em um cenário de uma globalização que, se lida como uma tendência pela emancipação das liberdades econômicas dos vínculos políticos territoriais, deveria levar a um repensar das modalidades de exercício da soberania estatal e de quais finalidades a soberania estatal deve hoje corresponder, a começar pelo incentivo à eficiência do sistema público.

Parece mais razoável, nessa perspectiva, buscar o aspecto da responsabilidade que há nas liberdades econômicas, ${ }^{17}$ em conformidade com uma inspiração enraizada na Constituição e que, não por acaso, lançou uma imprevisível dose de atenção em princípios constitucionais, como o da participação dos trabalhadores na gestão das empresas, em que se pode encontrar uma modalidade, por assim dizer, de solidariedade produtiva. Por outro lado, o mesmo princípio da subsidiariedade, que recentemente ascendeu à categoria constitucional ${ }^{18}$ e que se coloca em uma relação

\footnotetext{
17 TREMONTI, G. La paura e la speranza. Europa: la crisi globale che si avicina e la via per superarla. Milano: Garzanti Libri, 2008.

18 Ver Art. 118 da Constituição da Itália: As funções administrativas são atribuições dos municípios, salvo quando para garantir sua realização uniforme sejam atribuídas às Províncias, às Cidades Metropolitanas, às Regiões e ao Estado, com base nos princípios da subsidiariedade, da diferenciação e da adequação. Municípios, Províncias e Cidades metropolitanas são titulares de funções administrativas próprias e das que lhes forem conferidas por leis do Estado ou das Regiões, no âmbito das respectivas competências. A lei do Estado regula as formas de coordenação entre o Estado e as Regiões nos domínios referidos nas alíneas b) e h) do segundo parágrafo do Artigo 117, e disciplina também as formas de acordos e a coordenação no domínio da proteção do patrimônio cultural. O Estado,
} 
de consequência com aquela inspiração, sugere a possibilidade, não puramente ideal, mas concretamente praticável, de fortalecer a relação entre iniciativas individuais e necessidades coletivas, segundo um modelo de realizações dos direitos sociais que inverte a tendência de se realizarem apenas por dependência do crescimento da arrecadação fiscal e, assim, de dissuadir o dinamismo econômico. Resta apenas dizer que, nessa ótica da subsidiariedade, está também considerado o processo de regionalização dos direitos e que, por esse processo, sem que se avance em uma discussão quanto à vocação geral, admitem-se a definição e equilíbrios a partir de concretas realidades territoriais.

É impossível omitir, quando se percorre a relação entre a Constituição e a liberdade individual, a difícil e já bem debatida questão dos chamados "novos direitos". Podem ser dados como amplamente conhecidos os termos da discussão interpretativa que a questão suscitou, e continua a suscitar, pelo que preciso apenas lembrar o ponto central desse tema: ou seja, se seria possível deduzir outros direitos da pessoa, imediata e diretamente do Art. $2^{\mathrm{o}}$ da Constituição ${ }^{19}$ e da cláusula geral de reconhecimento dos direitos, e se por ela seriam constitucionalmente controláveis direitos de análoga consistência constitucional aos formalmente estabelecidos pelo Texto Constitucional; ou se sua nucleação hermenêutica deve ser ao menos filtrada por via das matérias constitucionais específicas, já preordenadas para protegerem o indivíduo.

Não cabe discutir aqui se a controvérsia brevemente invocada traduz alguma artificialidade, especialmente em relação ao iter a ser observado. Isto é, se deve ser mais ou menos ortodoxo do que os habituais cânones da interpretação jurídica, e se sempre se alcançará a identificação constitucional de um "novo" direito e, o que mais conta, quando é o caso de afirmar sua elevação ao nível constitucional com as sérias implicações que disso decorrem. Parece mais relevante constatar que pode se revelar idônea a nucleação de direitos não expressamente estabelecidos, como efetivamente tem ocorrido, de modo a contribuir à complementação da esfera de proteção do indivíduo (o direito ao nome, à imagem, etc.), confirmando, assim, o potencial evolutivo ínsito nas disposições constitucionais voltadas à tutela da dimensão privada e dos múltiplos bens que integram seu âmbito de proteção.

Não se pode, todavia, esconder - e aqui é intuitiva a referência às temáticas denominadas bioéticas - que a reivindicação de novos direitos também é portadora da radical prevalência da autodeterminação individual e de seus objetivos, seja em relação a outros direitos que podem resultar comprometidos, seja em relação a valores basilares da convivência coletiva com os quais estejam fortemente envolvidos.

as Regiões, as Cidades Metropolitanas, as Províncias e os Municípios devem promover a iniciativa autônoma dos cidadãos, individualmente e em associações, para a realização de atividades de interesse geral, com base no princípio da subsidiariedade. (N.T. Versão da última atualização de abril de 2012, disponível no site da legislação vigente, em: www.normattiva.it)

19 Art. $2^{\circ}$ da Constituição Italiana, de 1947: A República reconhece e garante os direitos invioláveis do homem, seja como indivíduo, seja nas formações sociais onde desenvolve sua personalidade, e exige o cumprimento dos deveres inderrogáveis de solidariedade política, econômica e social. (N.T. Versão da última atualização de abril de 2012, disponível no site da legislação vigente, em: www.normattiva.it). 
Por isso, em casos similares, a reivindicação em favor da autonomia individual e da imunidade das escolhas privadas se revela, ao contrário do que se gostaria, nada inócua; não se pode, assim, aplicar aquele pressuposto da coexistência dos direitos que, como se recordava de início, faz corpo com as liberdades modernas e que lhes permitiu exprimir todos aqueles efeitos inegavelmente progressivos: se é assim, está fora de contexto aquele puro e simples apelo às liberdades negativas, que declina todas as responsabilidades dos confrontos dos direitos que se opõem às expectativas individuais e que rejeita qualquer hipótese de ponderação, vendo-as como nada mais do que indevidas tentativas de condicionamento.

Discurso análogo pode ser feito, agora a partir de uma aplicação muito seca e unilateral da visão antimajoritária da liberdade, por reivindicações que assumem abertamente um significado de ruptura nos confrontos com éticas públicas consolidadas, em torno dos quais se realizaram delicados percursos de integração coletiva e de organização comunitária que também encontram respaldo em princípios constitucionais. Vale lembrar que tais princípios, segundo a intuição smendiana, são irredutíveis ao mero testemunho do relativo: expressam, em vez disso, um fundado e coerente desenho de convivência social.

À luz dos temas discutidos, cabe destacar também o ativismo judicial que foi registrado nessa matéria, tanto em sede interna quanto no que se manifesta a articulação multinível adquirida pelos direitos porque, para além de qualquer outra consideração, ficou claro o quanto é prioritária e irrenunciável uma atenta política das liberdades que restitua à lei a sua idoneidade para governar as inéditas dimensões de conflitualidade que se abrem atualmente nessas áreas e com as quais o constitucionalismo tem de se confrontar. 
